\title{
Incidence of the African Rice Gall Midge (AfRGM), Orseolia oryzivora H. \& G. in Relation with Period of Rice Transplanting in the Kou Valley, Burkina Faso
}

\author{
Karim Sama1, Souleymane Nacro ${ }^{2 *}$, Cheikh Thiaw $^{3}$, Dona Dakouo ${ }^{2}$ \\ ${ }^{1}$ Université Polytechnique de Bobo-Dioulasso, Bobo Dioulasso, Burkina Faso \\ ${ }^{2}$ Institut de l'Environnementet de Recherches Agricoles (INERA), Bobo-Dioulasso, Burkina Faso \\ ${ }^{3}$ Université Cheick Anta Diop, Dakar Fann, Sénégal \\ Email: "snacro2006@yahoo.fr
}

Received 16 February 2016; accepted 11 April 2016; published 15 April 2016

Copyright (C 2016 by authors and Scientific Research Publishing Inc.

This work is licensed under the Creative Commons Attribution International License (CC BY).

http://creativecommons.org/licenses/by/4.0/

c) (i) Open Access

\begin{abstract}
The African Rice Gall Midge, Orseolia oryzivora H. \& G., is an important insect pest recorded in 20 countries in Sub-Sahara Africa. In Burkina Faso, the insect pest particularly prevails in Western and South-Western of the country where both biotic and abiotic conditions favor its development. The insect pest can damage up to $60 \%$ of rice tillers in Western Burkina Faso. A study was conducted during the 2011 wet season in the Kou Valley, located $25 \mathrm{~km}$ North-West of Bobo-Dioulasso, Western Burkina Faso. Its objective was to evaluate the damage of this insect pest in farmers' fields in relation with rice transplanting periods. The Kou Valley rice scheme, 1200 ha, was divided into two zones within which $\mathbf{4 8}$ farmers' fields were randomly selected in relation with rice transplanting periods: P1: 1st period; P2: 2nd period and P3: 3rd period; that is 16 fields per period. Both agronomic and entomological evaluations were performed each week starting from the 21th day after transplanting (DAT) up to 84 DAT. Results showed that the highest average damage level (16\% of galls) was recorded in the 3rd transplanting period. The highest larval and pupal parasitism was recorded in P3 at 84 DAT. Pupal parasitism due to Aprostocetus procerae Risbec was higher than larval parasitism due to Platygaster diplosisae Risbec. Lastly, the lowest yield (4.78 t/ha) was recorded in P3. These results can be used in the implementation of an integrated pest management strategy for this insect pest in the Kou Valley.
\end{abstract}

\section{Keywords}

Orseolia oryzivora, Transplanting Period, Gall, Parasitism, Aprostocetus procerae,

"Corresponding author.

How to cite this paper: Sama, K., Nacro, S., Thiaw, C. and Dakouo, D. (2016) ncidence of the African Rice Gall Midge (AfRGM), Orseolia oryzivora H. \& G. in Relation with Period of Rice Transplanting in the Kou Valley, Burkina Faso. Advances in Entomology, 4, 97-103. http://dx.doi.org/10.4236/ae.2016.42011 


\section{Introduction}

The African Rice Gall Midge (AfRGM), Orseolia oryzivora H. \& G., is one of the major insect pests in Burkina Faso [1]. This insect pest is particularly important in the Western and in the South Western regions of the country where it finds favorable biotic and abiotic conditions. After emerging on the rice leaf, the insect's larva migrates, due to humidity, between the sheath and the stem of the rice plant to feed inside the advancing zone of the tiller. Such a feeding creates the formation of a hollow tubular structure called gall, thereby impeding the formation of a panicle. The damages caused by the midge can reach up $60 \%$ in the South-West of the country [2] [3]. Authors [4] have shown that $1 \%$ of damage inflicted by the insect was associated with $2 \%$ of yield loss.

Because of the economic importance of that insect pest, it appears necessary to develop efficient and sustainable control methods to mitigate its effects. Authors [2] developed a chemical control formula against this insect pest but that method, besides being economically onerous, was also not environmentally-friendly and can be harmful to human health. Therefore, further research is now directed towards integrated control that sets a premium on biological and cultural methods that are more environmentally-friendly.

The objective of this study was to assess the impact of the African rice gall midge on rice fields of the Kou Valley with respect to the transplanting periods in a perspective of an integrated management of the insect pest.

\section{Material and Methods}

\subsection{Study Site}

The study was carried out on the rice growing scheme of the Kou Valley, a location situated at 25 km NorthWest of Bobo-Dioulasso, Western Burkina Faso. This location is characterized by biotic conditions (presence of alternative host plants year round) and abiotic conditions (temperature and relative humidity) favorable to the development of the AfRGM. The Kou Valley is a rice growing scheme of 1200 ha with a total water control; its geographical coordinates are $4^{\circ} 22^{\prime}$ West longitude; $11^{\circ} 22^{\prime}$ North latitude and an altitude of $300 \mathrm{~m}$. The Kou Valley rice scheme is plotted into eight blocks (with respect to irrigation canals) composed of farmers' plots.

In 2011, the highest rainfall $(271.5 \mathrm{~mm})$ was reported in August and the total rainfall of the year was 901.9 $\mathrm{mm}$ in 81 days. The lowest mean temperature $\left(21.8^{\circ} \mathrm{C}\right)$ was observed in December whereas October was the hottest month $\left(28.4^{\circ} \mathrm{C}\right)$ of the year. The relative humidity varied between $82 \%$ in August and $51 \%$ in December.

\subsection{Sampling Methods}

Forty-eight farmer fields were chosen with respect to three rice transplanting periods which correspond to three treatments: P1 (1st transplanting period), P2 (2nd transplanting period) and P3 (3rd transplanting period).

The first transplanting period included farmers' fields transplanted between the 3rd and the 8th of July 2011. All these fields were chosen in zone 1 composed of four blocks (1, 2, 3 and 4).

The second transplanting period included farmers' fields transplanted between the 20th and the 25th of July 2011. All these fields were located in zone 2 which also included four blocks (5, 6, 7 and 8). The third transplanting period (P3) included all the fields that were transplanted after August the 4th 2011.

The choice of farmers' fields for this experimentation was done in consultation with farmers' cooperatives and the extension staff in the Kou Valley.

Rice growers of the Kou Valley benefitted in the past several trainings from the Institute for Environment and Agricultural Research and from the Integrated Production and Pest Management Program. New released rice varieties including FKR $62 \mathrm{~N}$, TS2, FKR $56 \mathrm{~N}$, FKR $60 \mathrm{~N}$ and organic manure (this manure was prepared by composting rice straw) that are used by farmers are the result of these trainings. Therefore, the 48 farmers were left to freely implement their own agricultural practices.

Soil analysis was not done prior to this study but soils in the Kou Valley are known to be mainly clayey and poor in organic matter. Rice plots were irrigated twice a week from a natural water source located about $8 \mathrm{~km}$. 
Rice plots were hand-weeded twice (before first urea dressing and before second urea dressing) or post-germination herbicides were applied twice (before first urea dressing and before second urea dressing).

\subsection{Observations in the Fields and the Laboratory}

Twenty rice hills were randomly chosen in each selected field and their tillers were counted once a week, from the 21st day after transplanting (DAT) to the 84th DAT that is 10 series of observations.

Twenty rice galls were taken from every farmer's field once a week as from 21st DAT and dissection was done in the laboratory for the counting of the AfRGM larvae parasitized by Platygaster diplosisae (Hymenoptera: Platygastridae) as well as the number of the insect pest pupae parasitized by Aprostocetus procerae (Hymenoptera: Eulophidae).

\subsection{Rice Harvesting and Yield Assessment}

When rice matured, 20 hills were randomly chosen and harvested. One thousand seeds from these 20 hills were sampled to determine their weight which we adjusted to the $14 \%$ humidity ratio. Yield quadrates of $1 \mathrm{~m}^{2}$ were implemented in each selected farmer' field. The harvested product was threshed, winnowed and weighed. The weight was adjusted to the $14 \%$ humidity ratio (because this is an international standard that indicates that the rice grain is appropriately dried when it contains a maximum of $14 \%$ water) and extrapolated to ha.

\subsection{Methods of Calculation and Data Analysis}

Average level of damage, average of larval parasitism and average pupal parasitism were calculated as follows:

$\checkmark$ Average level of damage $=\left(\sum\right.$ of galls in 20 hills $/ \sum$ tillers in 20 hills $) \times 100$

$\checkmark$ Average larval parasitism $=\left(\sum\right.$ of parasitized larvae in 20 galls $/ \sum$ total observed larvae in 20 galls $) \times 100$

$\checkmark$ Average pupal parasitism $=\left(\sum\right.$ of parasitized pupae in 20 galls $/ \sum$ total observed pupae in 20 galls $) \times 100$

The analysis of variance (ANOVA) was done with the $\mathrm{R}$ version 2.15 .1 software. The separation of means was done using the Student Newman Keuls (SNK) test at 5\% probability.

\section{Results}

\subsection{Effect of Transplanting Period on the Average Number of Tillers}

The ANOVA of the average number of tillers revealed significant differences between the treatments on the 42nd and the 63rd DAT, a highly significant difference on the 35th DAT and very highly significant differences on the 21st, 28th, 49th, 70th, 77th and 84th DAT (Figure 1). Thus, at 21st DAT the number of tillers in P1 was higher than that registered in treatment P2 and P3. In contrast, the average number of tillers (154) recorded in P2 was higher than that recorded in P3. On the 28th DAT, P1 scored an average number that was very significantly different from the one recorded in P2 and P3. In contrast, no significant difference was shown between treatments P2 and P3. On the $35^{\text {th }}$ DAT, the same trend as the one observed on the 28th DAT was revealed. From the 42nd to the 49th DAT, P2 respectively showed a much higher number of tillers than the one recorded in P1 and

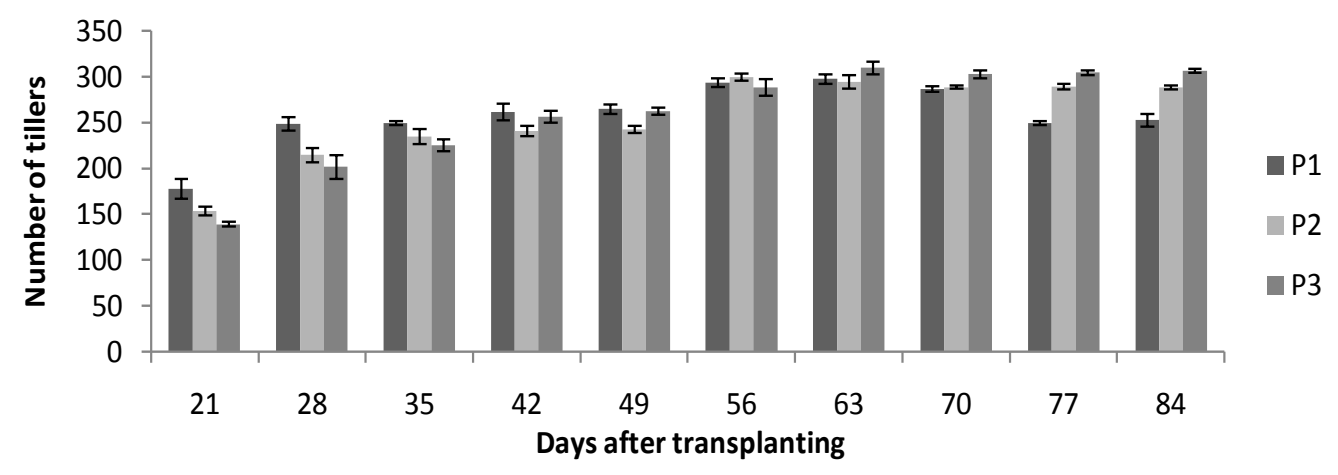

Figure 1. Effect of transplanting period on the number of rice tillers over time. P1, P2 and P3 represent respectively the first, the second and the third transplanting period. 
P3 for respective levels of probability of $P=0.008$ and $P<0.001$. On the 63rd DAT, the reverse tendency was evidenced and the number of tillers recorded in P3 was for the first time significantly higher than the one recorded in P2. However, no significant difference was seen between P3 and P1 on one hand, and P1 and P2 on the other hand. A comparison of treatments on the 70th DAT showed an average number of tillers recorded in P3 higher than the one shown in P1 and P2. No significant difference was found between P1 and P2. At 77th and 84th DAT, the ANOVA revealed significant differences between treatments. Thus, P3 showed a very significantly higher average number of tillers than P1 and P2 at 5\% probability level.

\subsection{Evolution of the Average Level of Damage}

The ANOVA performed on the average level of damage revealed significant differences between treatments at 70th DAT and highly significant differences at 77th and 84th DAT. Thus, on the 70th DAT, the average damage (4.55\%) registered in P2 was significantly different from the one observed in P1 for a probability level of $P=$ 0.006 (Table 1). In contrast, no significant difference was shown between P2 and P3 on one hand, and between P1 and P3 on the other hand. On the 77th DAT, P3 was very highly different from P2 and P1 at 5\% probability level. On the same day, P2 was also very significantly different from P1. The same trend was observed on the $84^{\text {th }}$ DAT. The highest damage level (16\%) was observed in P3.

\subsection{Evolution of Larval Parasitism by Platygaster diplosisae}

Table 2 presents the effect of transplanting period on the percentage of larval parasitism with respect to time. A significant difference between treatments was evidenced on the 63rd DAT and very highly significant differences were observed on the 70th, 77th and 84th DAT. Thus, on the 63rd DAT, P3 was significantly higher than P2 with a probability level of $P=0.007$. In contrast, no significant difference was seen between P1 and P3 on one hand and, betweenP1 and P2 on the other hand (Table 2). The ANOVA revealed that on the 70th DAT, P3 was very highly different from P1 and P2. In fact, from the 70th to the 84th DAT, there were always significant differences between treatments, P3 showing the highest larval parasitism.

Table 1. Effect of period of transplanting on the average percentage of galls over time.

\begin{tabular}{ccccccccccccc}
\hline \multicolumn{10}{c}{ Days after transplanting } \\
\hline Treatments & 21 & 28 & 35 & 42 & 49 & 56 & 63 & 70 & 77 & 84 \\
P1 & 0 & 0 & 0 & $1.18 \mathrm{a}$ & $1.79 \mathrm{a}$ & $1.90 \mathrm{a}$ & $1.74 \mathrm{a}$ & $2.11 \mathrm{~b}$ & $2.92 \mathrm{c}$ & $5.73 \mathrm{c}$ \\
P2 & 0 & 0 & 0 & $0.13 \mathrm{a}$ & $0.57 \mathrm{a}$ & $1.03 \mathrm{a}$ & $1.77 \mathrm{a}$ & $4.55 \mathrm{a}$ & $5.69 \mathrm{~b}$ & $9.4 \mathrm{~b}$ \\
P3 & 0 & 0 & 0 & $0.80 \mathrm{a}$ & $2.7 \mathrm{a}$ & $2.50 \mathrm{a}$ & $1.62 \mathrm{a}$ & $3.63 \mathrm{ab}$ & $6.96 \mathrm{a}$ & $16 \mathrm{a}$ \\
Probability & & & & 0.469 & 0.148 & 0.135 & 0.05 & 0.006 & $<0.001$ & $<0.001$ \\
Level of significance & & & & NS & NS & NS & NS & S & VHS & VHS \\
\hline
\end{tabular}

Numbers followed by the same letter are not significantly different at 5\% probability. S: significant; NS: no significant; VHS: very highly significant; P1, P2 and P3 represent respectively the first, the second and the third period of transplanting.

Table 2. Effect of period of transplanting on the average percentage of AfRGM parasitized larva over time.

\begin{tabular}{|c|c|c|c|c|c|c|c|c|c|c|}
\hline \multicolumn{11}{|c|}{ Days after transplanting } \\
\hline Treatments & 21 & 28 & 35 & 42 & 49 & 56 & 63 & 70 & 77 & 84 \\
\hline $\mathrm{P} 1$ & 0 & 0 & 0 & 0 & $8.52 \mathrm{a}$ & 13.65 a & $13.24 \mathrm{ab}$ & $10.67 \mathrm{~b}$ & $9.44 \mathrm{~b}$ & $10.64 \mathrm{c}$ \\
\hline $\mathrm{P} 2$ & 0 & 0 & 0 & 0 & $5.20 \mathrm{a}$ & $10.42 \mathrm{a}$ & $12.02 \mathrm{~b}$ & $11.32 \mathrm{~b}$ & 25.48 a & $33.75 \mathrm{~b}$ \\
\hline P3 & 0 & 0 & 0 & 0 & $6.03 \mathrm{a}$ & $9.55 \mathrm{a}$ & $24.23 \mathrm{a}$ & $26.31 \mathrm{a}$ & $32.80 \mathrm{a}$ & $43.10 \mathrm{a}$ \\
\hline Probability & & & & & 0.189 & 0.205 & 0.007 & $<0.001$ & $<0.001$ & $<0.001$ \\
\hline Level of significance & & & & & NS & NS & $\mathrm{S}$ & VHS & VHS & VHS \\
\hline
\end{tabular}

Numbers followed by the same letter are not significantly different at 5\% probability. S: significant; NS: no significant; VHS: very highly significant; P1, P2 and P3 represent respectively the first, the second and the third period of transplanting. 


\subsection{Evolution of Pupal Parasitism due to Aprostocetus procerae}

The results on pupal parasitism due to Aprostocetus procerae are presented in Table 3. There was no pupal parasitism till 56 DAT. The ANOVA revealed significant differences between treatments on the $77^{\text {th }}$ and the $84^{\text {th }}$ DAT. Thus, the average pupal parasitism in P3 was always significantly higher than those ones found in P1 and P2. The highest pupal parasitism (55.65\%) was recorded in P3 on the 84th DAT.

\subsection{Average Yield and Weight of 1000 Rice Grains}

The average yield and weight of 1000 rice grains are reported in Table 4. The ANOVA performed on the yield revealed significant differences between treatments. Thus, the average yields of P1 and P2 were significantly different from that of P3 with respective values of 5.76 metric tons /ha and of 5.77 metric tons /ha against 4.78 metric tons/ha for T3. No significant difference was shown between the yields of P1 and P2.

The average yield trend regarding the yields was observed regarding the 1000 rice grains yield. In fact, P1 and P2 showed an average 1000 rice grains weight that was significantly higher than the one in P3 for a probability level of $P=0.03$.

\section{Discussion}

The transplanting periods significantly influenced rice tillering in the course of our study. The maximal tillering was observed between the 56th DAT in P2 and the 63rd DAT in P1 and P3. Our findings agree with those reported by [5] and [6]. In fact, according to these authors, rice tillering is maximal between the 50th and the 60th DAT or between the 50th and the 67th DAT. The highest average number of tillers was recorded in P3 towards the end of the observations. P3 was also the most infested treatment by the AfRGM. Author [7] also reported the highest average number of tillers on the 81st DAT in the 3rd transplanting date in Boulbi, Burkina Faso. According to [8], infestations by the AfRGM resulted in the production of a variable number of tillers that will also be infested.

The transplanting periods showed that transplanting periods significantly influenced the average level of damage by the AfRGM during the reproductive phase of the rice plant. The damage of the insect pest that was

Table 3. Effect of period of transplanting on the average percentage of AfRGM parasitized pupa over time.

\begin{tabular}{cccccccccccc}
\hline \multicolumn{10}{c}{ Days after transplanting } \\
\hline Treatments & 21 & 28 & 35 & 42 & 49 & 56 & 63 & 70 & 77 & 84 \\
P1 & 0 & 0 & 0 & 0 & 0 & $0.69 \mathrm{a}$ & $10.25 \mathrm{a}$ & $10.67 \mathrm{a}$ & $13.06 \mathrm{~b}$ & $21.74 \mathrm{c}$ \\
P2 & 0 & 0 & 0 & 0 & 0 & $0.11 \mathrm{a}$ & $9.23 \mathrm{a}$ & $11.32 \mathrm{a}$ & $14.54 \mathrm{~b}$ & $31.19 \mathrm{~b}$ \\
P3 & 0 & 0 & 0 & 0 & 0 & $0.01 \mathrm{a}$ & $11.01 \mathrm{a}$ & $26.31 \mathrm{a}$ & $32.67 \mathrm{a}$ & $55.65 \mathrm{a}$ \\
Probability & & & & & & 0.405 & 0.19 & 0.075 & $<0.001$ & $<0.001$ \\
Level of significance & & & & & & & & & & & \\
\hline
\end{tabular}

Numbers followed by the same letter are not significantly different at 5\% probability. NS: no significant; VHS: very highly significant; P1, P2 and P3 represent respectively the first, the second and the third period of transplanting.

Table 4. Average yield (t/ha) and average 1000 grains weight $(\mathrm{g})$ according to the period of transplanting.

\begin{tabular}{ccc}
\hline Periods of transplanting & Yield (t/ha) & 1000 Grain weight $(\mathrm{g})$ \\
\hline P1 & $5.76 \mathrm{a}$ & $25.3 \mathrm{a}$ \\
P2 & $5.77 \mathrm{a}$ & $25.38 \mathrm{a}$ \\
P3 & $4.78 \mathrm{~b}$ & $24.33 \mathrm{~b}$ \\
Probability & 0.02 & 0.03 \\
Level of significance & $\mathrm{S}$ & $\mathrm{S}$
\end{tabular}

Numbers followed by the same letter are not significantly different at 5\% probability. S: significant. P1, P2 and P3 represent respectively the first, the second and the third period of transplanting. 
low at the early tillering stage of the plant increased importantly during the reproductive phase, irrespective of the transplanting period. These results are comparable to those reported by [9] in Karfiguéla, an irrigated rice scheme, Western Burkina Faso. Authors [10] reported similar results in Nigeria. The highest damage was recorded in the third transplanting period. This result could be explained by the late transplanting (with respect to the normal season) of rice. In fact, in P3, rice was transplanted after August 4th, whereas the two other treatments were implemented before July 25th. References [11] and [12] showed that the AfRGM damages were more severe on seedlings that were transplanted late than early established ones. Reference [13] stressed on the spreading of rice planting over time in the same area that fosters the multiplication of the number of generations of the AfRGM by providing the insect pest with successive habitats and food, thus enabling the reproduction of the insect pest populations throughout the cropping season, with more damage in the fields that were transplanted late. The $60 \%$ damage reported by [2] is far higher than the maximum $16 \%$ recorded in this study. That difference could be explained not only by differences between locations, but also and foremost by the fact that the Kou Valley farmers were provided with new varieties supposed to be more or less tolerant to the AfRGM. To that fact, could be added the important work implemented by the Integrated Production and Pest Management Program (IPPM) through the participative training provided to rice farmers in Farmers' Field Schools in Burkina Faso for a decade (2001-2009). Larval parasitism of AfRGM was recorded late irrespective of the planting period. This larval parasitism was low as from the 49th DAT, but became high during the reproductive phase of the rice plant and towards the end of the crop life cycle. The same trend was observed regarding pupal parasitism due by A. procerae where the maxima average ratios of parasitized pupae were recorded late in the cropping season. Reference [2] reported a high mortality of the AfRGM at the end of the wet season in Western Burkina Faso. In our study, pupal parasitism was higher than the larval one. Our findings did not agree with those reported by [2] in Burkina Faso and by [14] in Nigeria who showed that the larval parasitism of the AfRGM was higher. In contrast, our results agree with [15] findings in Boulbi, Central Burkina Faso. The lowest yield and weight of 1000 grains of rice were recorded in P3, the latest transplanting period although the ANOVA did not show any significant difference between treatments. Our results are similar to the findings reported by authors like [7] [10] and [16]. These authors stressed the importance of early transplanting on crop yield.

\section{Conclusion}

These results indicate that the incidence of the AfRGM on rice crop in the Kou Valley depends on the period of transplanting. The more rice is transplanted late in the season, the more it is likely to be infested by the AfRGM and the more the yield will be reduced. The combined parasitism due to two Hymenopteran parasitoids was higher in late transplanted fields but it got established late so that it could not prevent AfRGM early damage. Transplanting rice before August appears to be a relatively efficient cultural control method for the AfRGM. That method could be easily combined with other methods such as the preservation of natural enemies associated with the insect pest, the use of resistant/tolerant varieties in order to develop an integrated management strategy for the AfRGM in the Kou Valley rice scheme.

\section{Acknowledgements}

This work was supported by the International Institute for Education, USA, through the Alumni Impact Grant of the Hubert Humphrey Fellowship Program awarded to the second author.

\section{Conflict Interest Statement}

This article reports on research work and none of the authors has conflict interest with the funding institution.

\section{References}

[1] Ba, N.M., Dakouo, D., Nacro, S. and Karamage, F. (2007) Seasonal Abundance of Lepidopterous Stemborers and Diopsid Flies in Irrigated Fields of Cultivated (Oryza sativa) and Wild Rice (Oryza longistaminata) in Western Burkina Faso. International Journal of Tropical Insect Science, 28, 30-36.

[2] Dakouo, D., Nacro, S. and Sié, M. (1988) Evolution saisonnière des infestations de la cécidomyie du riz Orseolia oryzivora H. et G. (Diptera, Cecidomyiidae) dans le sud-ouest du Burkina Faso. Insect Science and Its Application, $\mathbf{9}$, 469-473. 
[3] Ba, N.M. (2003) Cycle annuel de la cécidomyie du riz, Orseolia oryzivora Harris et Gagné (Diptera: cecidomyidae) en relation avec ses plantes hôtes, ses parasitoïdes et certaines pratiques culturales au Sud-ouest du Burkina Faso. Thèse de Doctorat de l’Université de Ouagadougou, Ouagadougou, 121 p.

[4] Nacro, S., Heinrichs, E.A. and Dakouo, D. (1996) Estimation of Rice Yield Losses Due to the African Rice Gall Midge, Orseolia oryzivora Harris and Gagne. International Journal of Pest Management, 42, 331-334.

[5] Arraudeau, M.A. and Vergara, B.S. (1992) Manuel illustré de riziculture pluviale. IRAT-CIRAD, 284 p.

[6] Nacro, S., Barro, S.A., Sawadogo, L., Gnamou, A. and Tankoano, H. (2006) The Effect of Planting Date on the African Rice Gall Midge Orseolia oryzivora (Diptera: Cecidomyiidae) Damage under Irrigated Conditions in Boulbi, Central Burkina Faso. International Journal of Tropical Insect Science, 26, 227-232. http://dx.doi.org/10.1017/S1742758406454278

[7] Barro, S.A. (2004) Etude de l’importance économique de la cécidomyie africaine du riz, Orseolia oryzivora H. \& G. sur la plaine rizicole de Boulbi. Mémoire de fin d’études, option Agronomie. Institut du Développement Rural, Université polytechnique de Bobo-Dioulasso, Bobo-Dioulasso, $62 \mathrm{p}$.

[8] Nacro, S. (1994) Analyse d'un système tritrophique: la cécidomyie du riz et ses parasitoïdes au Burkina Faso. Thèse de Doctorat, Université de Rennes I, Rennes, 118 p.

[9] Sibomana, I. (1999) Etude de l'effet des pratiques culturales sur la cécidomyie africaine du riz: cas de la fumure azotée et des écartements entre les plants de riz. Mémoire de fin d'études. Institut du Développement Rural (IDR), Université Polytechnique de Bobo-Dioulasso, Bobo-Dioulasso, 96 p.

[10] Williams, C.T., Harris, K.M. Ukwungwu, M.N., Nacro, S., Dakouo, D., Nwilene, F.E., Singh, B.N. and Okhidievbie, O. (2000) African Rice Gall Midge. Research Guide. WARDA/ADRAO, Bouaké, Côte d'Ivoire \& CABI, Slough, 28 p.

[11] Umeh, E. (1998) Aspects of the Biology and Natural Biological Control of the African Rice Gall Midge, Orseolia oryzivora H. \& G. (Diptera: Cecidomyiidae). WARDA/IITA, Ibadan, 12-16 October, 7 p.

[12] Nwilene, F.E., Williams, C.T., Ukwungwu, M.N., Dakouo, D., Nacro, S., Hamadoun, H, Kamara, S.I., Okhidievbie, O., Abamu, F.J. and Adam, A. (2002) Reactions of Differential Rice Genotypes to African Rice Gall Midge in West Africa. International Journal of Pest Management, 48, 195-201. http://dx.doi.org/10.1080/09670870110103890

[13] ADRAO (2000) Une petite mouche à gros problèmes: la cécidomyie africaine des galles du riz. Côte d’Ivoire, 20-26.

[14] Umeh, E.D.N. and Joshi, R.C. (1993) Aspects of the Biology, Ecology and Natural Biological Control of the African Rice Gall Midge, Orseolia oryzivora Harris and Gagné (Dipt., Cecidomyiidae) in South East Nigeria. Journal of Applied Entomology, 116, 391-398. http://dx.doi.org/10.1111/j.1439-0418.1993.tb01212.x

[15] Tankoano, H. (2005) Impact de la date de repiquage du riz sur la Cécidomyie africaine du riz, Orseolia oryzivora H. \& G. et son cortège parasitaire sur la plaine rizicole de Boulbi. Université Polytechnique de Bobo-Dioulasso, Bobo-Dioulasso, $103 \mathrm{p}$.

[16] Nacro, S. (1995) Les foreurs de tige du riz. Communication présentée au séminaire international en lutte biologique, Bobo-Dioulasso, du 7 au 20 mai 1995, 14 p. 